\title{
Influence of a probiotic soy product on fecal microbiota and its association with cardiovascular risk factors in an animal model
}

Daniela CU Cavallini ${ }^{*}$, Juliana Y Suzuki ${ }^{1}$, Dulcinéia SP Abdalla ${ }^{2}$, Regina C Vendramini ${ }^{3}$, Nadiége D Pauly-Silveira ${ }^{1}$, Mariana N Roselino ${ }^{1}$, Roseli A Pinto ${ }^{1}$ and Elizeu A Rossi ${ }^{1}$

\begin{abstract}
Background: Previous work showed that daily ingestion of an aqueous soy extract fermented with Enterococcus faecium CRL 183 and Lactobacillus helveticus 416, supplemented or not with isoflavones, reduced the total cholesterol and non-HDL-cholesterol levels, increased the high-density lipoprotein (HDL) concentration and inhibited the raising of autoantibody against oxidized low-density lipoprotein (ox-LDL Ab) and the development of atherosclerotic lesions.

Objective: The aim of this study was to characterize the fecal microbiota in order to investigate the possible correlation between fecal microbiota, serum lipid parameters and atherosclerotic lesion development in rabbits with induced hypercholesterolemia, that ingested the aqueous soy extract fermented with Enterococcus faecium CRL 183 and Lactobacillus helveticus 416.

Methods: The rabbits were randomly allocated to five experimental groups $(n=6)$ : control $(C)$, hypercholesterolemic $(H)$, hypercholesterolemic plus unfermented soy product (HUF), hypercholesterolemic plus fermented soy product (HF) and hypercholesterolemic plus isoflavone-supplemented fermented soy product (HIF). Lipid parameters and microbiota composition were analyzed on days 0 and 60 of the treatment and the atherosclerotic lesions were quantified at the end of the experiment. The fecal microbiota was characterized by enumerating the Lactobacillus spp., Bifidobacterium spp., Enterococcus spp., Enterobacteria and Clostridium spp. populations.

Results: After 60 days of the experiment, intake of the probiotic soy product was correlated with significant increases ( $P<0.05)$ on Lactobacillus spp., Bifidobacterium spp. and Enterococcus spp. and a decrease in the Enterobacteria population. A strong correlation was observed between microbiota composition and lipid profile. Populations of Enterococcus spp., Lactobacillus spp. and Bifidobacterium spp. were negatively correlated with total cholesterol, non-HDL-cholesterol, autoantibodies against oxidized LDL (oxLDL Ab) and lesion size. HDL-C levels were positively correlated with Lactobacillus spp., Bifidobacterium spp., and Enterococcus spp. populations.
\end{abstract}

Conclusion: In conclusion, daily ingestion of the probiotic soy product, supplemented or not with isoflavones, may contribute to a beneficial balance of the fecal microbiota and this modulation is associated with an improved cholesterol profile and inhibition of atherosclerotic lesion development.

Keywords: probiotics, Enterococcus faecium CRL 183, fecal microbiota, lipid parameters

\footnotetext{
* Correspondence: daniducavallini@ig.com.br

${ }^{1}$ Department of Food \& Nutrition, School of Pharmaceutical Sciences, Sao

Paulo State University, Araraquara, SP, Brazil

Full list of author information is available at the end of the article
} 


\section{Background}

The human intestinal microbiota plays an important role in maintaining human health, preventing colonization by pathogenic microorganisms, breaking down dietary compounds, producing nutrients and keeping the intestinal mucosa in a healthy state. Other important functions have begun to be unveiled over the past few years, suggesting that the effects of the gut microbiota may be more profound, influencing complex processes such as glucose and lipid metabolism, predisposition to obesity and disorders mediated by the immune system, including inflammatory bowel disease, autoimmune conditions and allergic reactions $[1,2]$.

Cardiovascular diseases (CVD) are the main cause of death around the world and dyslipidemia is a key factor in susceptibility to coronary heart disease (CHD) and other atherosclerotic diseases [3].

Recent research has afforded strong evidence suggesting that the gut microbiota could influence host cholesterol metabolism [4]. The mechanisms involved in this effect include modifications of bile acids that affect enterohepatic circulation, de novo synthesis of bile acids and cholesterol absorption and inhibition of lipoprotein lipase $[5,6]$.

In previous studies, we have shown that daily ingestion of an aqueous soy extract fermented with Enterococcus faecium CRL 183 and Lactobacillus helveticus 416, supplemented or not with isoflavones, could improve the lipid profile in animal and human tests [7-10]. Using New Zealand rabbits, Cavallini et al. (2009) [11] demonstrated that the same probiotic product, with or without isoflavones, leads to a significant reduction of serum total cholesterol and non-high density lipoprotein-cholesterol (non-HDL-C), increases the high-density lipoprotein (HDL) level, inhibition of the raise of autoantibody against oxidized low-density lipoprotein (ox-LDL Ab) and slows the development of atherosclerotic lesions. In this study, we intend to characterize the fecal microbiota of rabbits that ingest the aqueous soy extract fermented with Enterococcus faecium CRL 183 and Lactobacillus helveticus 416, in order to investigate the possible correlation of specific modification of fecal microbiota, serum lipid parameters and atherosclerosis development.

\section{Material and Methods}

\section{Animals and experimental protocol}

Male New Zealand white rabbits $(\mathrm{n}=30$, 8-9 weeks old, weighing 2.5-3.0 Kg; obtained from Central Animal Facility of Sao Paulo State University, Botucatu, SP, Brazil) were housed in individual cages in temperature-controlled rooms $\left(22^{\circ} \mathrm{C} \pm 2^{\circ} \mathrm{C}\right)$, with a light-dark cycle of $12: 12 \mathrm{~h}$.

Rabbits were fed a chow diet (Purina, SP, Brazil) for 1 week to acclimatize the animals and then randomly allocated to five experimental groups $(\mathrm{n}=6)$ : control $(\mathrm{C})$, hypercholesterolemic $(\mathrm{H})$, hypercholesterolemic plus unfermented soy product (HUF), hypercholesterolemic plus fermented soy product (HF) and hypercholesterolemic plus isoflavone-supplemented fermented soy product (HIF).

The control group (C) was fed only on commercial rabbit food (Nutri Rabbit Special Chow Purina; nutritional make-up per $100 \mathrm{~g}: 23 \mathrm{~g}$ protein, $4 \mathrm{~g}$ fats, $49 \mathrm{~g}$ carbohydrates, $5 \mathrm{~g}$ fiber and $10 \mathrm{~g}$ minerals). The other groups (H, HUF, HF and HIF) were fed on the same rabbit diet, to which cholesterol (Sigma C 8503) had been added to induce hypercholesterolemia. The level of cholesterol added to the diet was adjusted during the experiment ( $1.0 \%$ down to $0.7 \%$ after 30 days), to maintain the animal healthy and the feed was prepared as previously described (Cavallini et al., 2009). The rabbits received restrict amounts $(125 \mathrm{~g} / \mathrm{d})$ of each diet and had free access to water during the experimental period.

The fermented soy product was processed at the Development and Production Unit for Soybean Derivatives (UNISOJA, Food and Nutrition Department of the School of Pharmaceutical Sciences, UNESP at Araraquara - SP, Brazil), using the method described by Rossi et al (1989). The bacterial inoculum consisted of $3 \%(\mathrm{v} / \mathrm{v})$ of a $1: 1$ mixture of Enterococcus faecium CRL 183 (probiotic microorganism, from Centro de Referencia para Lactobacilos - CERELA - Argentina) and Lactobacillus helveticus 416 (fermentation adjuvant, from Institute of Food Technology - ITAL - Campinas, Brazil). Isoflavone-suplemented fermented soy product was prepared by adding Isoflavin ${ }^{\circledR}$ (Galena, Brazil), before the fermentation, at $75 \mathrm{mg}$ (total isoflavone) per $100 \mathrm{~g}$. Fermented soy product, supplemented or not with isoflavones, exhibited cell viable counts between $10^{9}-10^{10} \mathrm{CFU} / \mathrm{mL}$. Unfermented soy product was prepared by chemical acidification of soy product basic mixture (without bacterial culture or isoflavone), to reach the same $\mathrm{pH}$ as the fermented soy product (4.4 - 4.6), by adding food-grade lactic acid (Synth, Sao Paulo, SP, Brazil). The chemical composition of the products is presented in Table 1.

Groups HUF, HF and HIF received, by gavage once a day, unfermented soy product $(2.8 \mathrm{~mL} / \mathrm{kg}$ body weight), fermented soy product ( $2.8 \mathrm{~mL} / \mathrm{kg}$ body weight) and isoflavone-supplemented fermented soy product $(2.8 \mathrm{~mL} / \mathrm{kg}$ body weight $-2.1 \mathrm{mg}$ of total isoflavone $/ \mathrm{kg}$ body weight), respectively.

The experiment was carried out for 60 days. The fecal microbiota, lipid parameters and atherosclerotic lesion development were analyzed before the start (T0) and at the end of the experimental period (T60).

The experimental design received approval ( $n^{\circ}$ 03/2007) from the Research Ethics Committee of the School of Pharmaceutical Sciences, UNESP at Araraquara (SP, Brazil). 
Table 1 Composition of unfermented soy product, fermented soy product and isoflavone-supplemented fermented soy product

\begin{tabular}{cccc}
\hline Composition & Unfermented Soy Product & Fermented Soy Product & Isoflavone-Supplemented Soy Product \\
\hline Protein $(\mathrm{g} / 100 \mathrm{~g})$ & $3.85 \pm 0.04$ & $3.90 \pm 0.00$ & $3.85 \pm 0.00$ \\
Fat $(\mathrm{g} / 100 \mathrm{~g})$ & $2.32 \pm 0.02$ & $2.30 \pm 0.08$ & $2.26 \pm 0.09$ \\
Carbohydrate $(\mathrm{g} / 100 \mathrm{~g})$ & $9.93 \pm 0.16$ & $9.70 \pm 0.15$ & $10.06 \pm 0.11$ \\
Ash (g/100 g) & $0.90 \pm 0.00$ & $0.90 \pm 0.07$ & $0.90 \pm 0.00$ \\
Moisture $(\mathrm{g} / 100 \mathrm{~g})$ & $83.00 \pm 0.16$ & $83.20 \pm 0.00$ & $82.93 \pm 0.17$ \\
Total isoflavone (mg/100 g) & $8.03 \pm 0.07$ & $8.04 \pm 0.01$ & $51.26 \pm 1.12$ \\
Daidzin (mg/100 g) & $2.00 \pm 0.03$ & $2.09 \pm 0.04$ & $4.68 \pm 0.27$ \\
Genistin (mg/100 g) & $5.76 \pm 0.05$ & $5.69 \pm 0.04$ & $6.72 \pm 0.02$ \\
Daidzein (mg/100 g) & $0.26 \pm 0.01$ & $0.26 \pm 0.01$ & $32.62 \pm 0.94$ \\
Genistein (mg/100 g) & - & - & $7.25 \pm 0.22$ \\
Final $\mathrm{pH}$ & 4.6 & 4.45 & 4.55 \\
\hline
\end{tabular}

Values represent mean \pm SEM $(n=3)$. Fermented soy product and isoflavone-supplemented soy product were fermented by a mixed culture of Enterococcus faecium CRL 183 and Lactobacillus helveticus 416.

\section{Stool collection}

Stools were collected from the cages for 24 hours at the each sampling time (days 0 and 60). Samples were collected in aseptic plastic bags, placed in anaerobic jars with gas-generating kits (Anaerobac, Probac, Brazil) and then analyzed for bacterial counts as soon as possible, as described below.

\section{Blood Sampling}

Blood was drawn from the marginal ear vein, after a 14 to 16-hour fast. The samples were centrifuged (3500 x g for $10 \mathrm{~min}$ ) and the serum taken for lipid profile determination. For the oxLDL Ab determination, plasma was first separated from the blood by centrifugation $(3500 \times \mathrm{g}$ for $10 \mathrm{~min}$ at $4^{\circ} \mathrm{C}$ ), then $1.0 \mathrm{mmol} / \mathrm{L}$ phenylmethylsulfonyl fluoride (Sigma Chemical), $2.0 \mathrm{mmol} / \mathrm{L}$ benzamidine (Sigma Chemical), $2.0 \mathrm{mg} / \mathrm{L}$ aprotinin (Sigma Chemical) and $20.0 \mathrm{mmol} / \mathrm{L} \mathrm{BHT} \mathrm{(Sigma} \mathrm{Chemical)} \mathrm{were} \mathrm{added} \mathrm{to}$ the samples of plasma.

\section{Analysis of Serum lipids}

The serum levels of total cholesterol (TC), high-density lipoprotein (HDL-C) and triglycerides were assayed in each rabbit, with the aid of specific enzyme kits. TC was measured by the cholesterol fast color method [12]. HDL-C was estimated by first selectively precipitating lipoproteins [13] and then applying the TC method to the supernatant. Non-HDL cholesterol was calculated by subtracting HDL-C from $\mathrm{TC}$ and was composed of the LDL+IDL+VLDL cholesterol fractions $[14,15]$.

\section{Detection of autoantibodies against oxidized LDL (oxLDL Abs)}

The autoantibodies against oxLDL were assayed in plasma by ELISA, as previously described [16,17]. The data were presented as milli Arbitrary Units (mAU/L).

\section{Analysis of atherosclerotic lesions}

After the 60 days of the experiment, the rabbits were heparinized and euthanized by an overdose of sodium phenobarbital (130 mg/kg body weight - Cristália, SP, Brazil) and the aorta was removed to analyze the macroscopic atherosclerotic lesions. The aorta was divided into the following segments: 1) aortic arch; 2) thoracic and abdominal aortas. The material was fixed overnight, at room temperature, in $10 \%$ buffered formaldehyde solution and stained with Sudan IV to reveal areas of atherosclerotic plaque [18]. The stained aorta was photographed with a digital camera (Sony) and the sudanophilic lesions were identified and quantified. The surface area of the atherosclerotic lesions was measured with an image analyzer system (Imagelab - USP - Brazil) and expressed as a percentage of the total aortic surface area covered by lesion.

\section{Analysis of fecal microbiota}

Each fecal sample (1 g) was homogenized in a stomacher, with sterile peptone water $(99 \mathrm{~g})$. Subsequent tenfold serial dilutions were plated in triplicate on the following selective media to distinguish bacterial genera: Enterococcus spp.: KF Streptococcus agar (Acumedia) [19]; Lactobacillus spp.: MRS agar (Merck, Darmstadt, Deutschland, Germany) [20]; Bifidobacterium spp.: Bifidobacterium iodoacetate medium 25 (BIM-25) [21]; Enterobacteria: MacConkey agar (Acumedia) [22]; Clostridium spp.: RCA agar (Difco, Le Point de Claix, France) [23]. Plates for Enterococcus spp. and Enterobacteria were incubated at $37^{\circ} \mathrm{C}$ for $48 \mathrm{~h}$. Plates for Lactobacillus spp., Clostridium spp. and Bifidobacterium spp were incubated anaerobically, in anaerobic jars with gas-generating kits, at $37^{\circ} \mathrm{C}$ for $48 \mathrm{~h}, 48 \mathrm{~h}$ and $72 \mathrm{~h}$, respectively.

\section{Statistical analysis}

Results are presented as means \pm standard deviations. One-way ANOVA was used to determine a significant 
difference between groups $(\mathrm{P}<0.05)$. Tukey's test was used to perform multiple comparisons between means. The difference between study periods was verified by Student's t-test. Correlations between cardiovascular risk factors and bacterial populations were assessed by Pearson's correlation test.

\section{Results}

\section{Lipid parameters and atherosclerotic lesion}

The effects of treatments on lipid parameters are shown in Table 2.

After 60 days of treatment, rabbits that received fermented soy product exhibited the greatest reduction $(\mathrm{p}<0.05)$ in $n-H D L-C(38.7 \%)$, relative to group $H$. Animal in the groups HF, HIF and HUF exhibited significantly lower TC levels than group $\mathrm{H}$ (38.1\%, $27.0 \%$ and $26.6 \%$ respectively).

The HDL-C level was higher in animals that received the fermented soy product, supplemented or not with isoflavones (55.2\%), and unfermented soy product (35.8\%), than in group H. However, statistical comparison of samples at different times showed that only the $\mathrm{HF}$ and $\mathrm{C}$ groups showed no reduction in HDL-C levels after 60 days of the experiment.

The animals fed a high cholesterol diet $(\mathrm{H})$ and unfermented soy product (HUF) exhibited a rapid rise in antioxLDL Ab $(\mathrm{P}<0.05)$, while the fermented soy product (HF) and fermented soy product supplemented with isoflavones (HIF) reduced the rise in this parameter during the experiment.

Comparisons of atherosclerotic lesion area in aortic segments are shown in Figure 1. The extent of atherosclerosis on the whole aorta demonstrated that animals treated with fermented soy product supplemented with isoflavones exhibited the lower percentage of aortic area covered with lesion $(19,0 \%)$, differing significantly from the group $\mathrm{H}(39,13 \%)$.

\section{Characterization of fecal microbiota}

The fecal bacterial counts of the different treatment groups are summarized in Table 3. At the start of the protocol the microbiota compositions of the rabbits groups were different $(\mathrm{p}<0.05)$, so that the comparison of times was more relevant.

After 60 days of treatment, animals that consumed only the hypercholesterolemic diet (group $\mathrm{H}$ ) showed a significant reduction in all bacteria groups studied, including the beneficial genera Bifidobacterium spp. and Lactobacillus spp. Rabbits fed a probiotic soy product (HF) and commercial chow $(C)$ showed a significant increase in Bifidobacterium spp. counts. The population of Lactobacillus spp. was increased in the animals that received fermented soy product, supplemented or not with isoflavones, and in the control group. Unfermented soy product was unable to increase or prevent the decrease of Bifidobacterium spp. and Lactobacillus spp. populations.

Fecal Enterococcus spp. population was significantly increased in the groups control (C), hypercholesterolemic plus unfermented soy product (HUF), hypercholesterolemic plus fermented soy product (HF) and hypercholesterolemic plus isoflavone-suplemented fermented soy product (HIF). All the treatment groups displayed a decrease in the Enterobacteria counts during the experiment. By the end of the study, the population of Clostridium spp. fell significantly in all groups, excepting in the animals of the hypercholesterolemic plus fermented soy product group (HF), compared to basal period (T0).

\section{Correlation of fecal microbiota and metabolic parameters} The analysis showed a strong negative correlation between serum concentrations of total cholesterol, nonHDL-C and autoantibody against oxidized LDL and area of atherosclerotic lesion, on one hand, and Enterococcus spp., Lactobacillus spp. and Bifidobacterium spp. counts,

Table 2 Serum lipids and oxLDL Abs among the groups

\begin{tabular}{|c|c|c|c|c|c|c|}
\hline Serum lipids & Time & $\mathrm{C}$ & $\mathrm{H}$ & HUF & $\mathrm{HF}$ & HIF \\
\hline \multicolumn{7}{|l|}{$\mathrm{TC}$} \\
\hline \multirow[t]{2}{*}{$(\mathrm{mg} / \mathrm{dL})$} & TO & $49.0 \pm 3.7^{\mathrm{aA}}$ & $42.0 \pm 2.8^{\mathrm{aB}}$ & $44.8 \pm 5.8^{\mathrm{aB}}$ & $45.3 \pm 5.1^{\mathrm{aB}}$ & $44.5 \pm 5.4^{\mathrm{aB}}$ \\
\hline & $\mathrm{T} 60$ & $53.3 \pm 6.2^{\mathrm{bA}}$ & $2556.5 \pm 120.3^{\mathrm{aA}}$ & $1876.3 \pm 233.6^{\mathrm{bA}}$ & $1583.8 \pm 86.3^{\mathrm{CA}}$ & $1867.5 \pm 251.7^{\mathrm{bA}}$ \\
\hline \multicolumn{7}{|l|}{ HDL-C } \\
\hline \multirow[t]{2}{*}{$(\mathrm{mg} / \mathrm{dL})$} & T0 & $31.5 \pm 2.3^{\mathrm{aA}}$ & $28.5 \pm 2.5^{\mathrm{aA}}$ & $31.50 \pm 3.6^{\mathrm{aA}}$ & $32.0 \pm 2.6^{\mathrm{aA}}$ & $31.8 \pm 1.1^{\mathrm{aA}}$ \\
\hline & $\mathrm{T} 60$ & $26.8 \pm 2.8^{\mathrm{aA}}$ & $16.8 \pm 2.8^{\mathrm{CB}}$ & $22.8 \pm 2.8^{\mathrm{abB}}$ & $32.0 \pm 2.6^{\mathrm{aA}}$ & $26.0 \pm 2.1^{\mathrm{aB}}$ \\
\hline \multicolumn{7}{|l|}{$\mathrm{n}-\mathrm{HDL}-\mathrm{C}$} \\
\hline \multirow[t]{2}{*}{$(\mathrm{mg} / \mathrm{dL})$} & T0 & $17.5 \pm 2.6^{\mathrm{aB}}$ & $13.5 \pm 2.9^{\mathrm{aB}}$ & $13.3 \pm 2.4^{\mathrm{aB}}$ & $13.3 \pm 3.0^{\mathrm{aB}}$ & $12.3 \pm 2.3^{\mathrm{aB}}$ \\
\hline & $\mathrm{T} 60$ & $26.5 \pm 4.4^{\mathrm{CA}}$ & $2539.8 \pm 120.2^{\mathrm{aA}}$ & $1853.5 \pm 231.8^{\mathrm{bA}}$ & $1557.8 \pm 86.6^{\mathrm{bA}}$ & $1841.5 \pm 249.8^{\mathrm{bA}}$ \\
\hline \multicolumn{7}{|l|}{ oxLDL Abs } \\
\hline \multirow[t]{2}{*}{$(\mathrm{mAU} / \mathrm{L})$} & T0 & $0.204 \pm 0.104^{\mathrm{aA}}$ & $0.339 \pm 0.129^{a B}$ & $0.323 \pm 0.105^{\mathrm{aB}}$ & $0.390 \pm 0.289^{\mathrm{aA}}$ & $0.338 \pm 0.166^{\mathrm{aA}}$ \\
\hline & $\mathrm{T} 60$ & $0.316 \pm 0.156^{\mathrm{bA}}$ & $1.809 \pm 0.514^{\mathrm{aA}}$ & $0.799 \pm 0.285^{\mathrm{bA}}$ & $0.553 \pm 0.296^{\mathrm{bA}}$ & $0.530 \pm 0.232^{\mathrm{bA}}$ \\
\hline
\end{tabular}

Values (in $\mathrm{mg} / \mathrm{dL}$ ) represent mean $\pm \mathrm{SEM}(\mathrm{n}=6) . \mathrm{C}=$ control; $\mathrm{H}=$ hypercholesterolemic; $\mathrm{HUF}=$ hypercholesterolemic plus unfermented soy product, $\mathrm{HF}=$ hypercholesterolemic plus fermented soy product, HIF = hypercholesterolemic plus isoflavone-supplemented fermented soy product. T0 = before the start of the study, $\mathrm{T} 60$ = end of the experiment. Statistical comparison of treatment groups: means with identical lower-case letters in the same row do not differ significantly $(P \leq 0.05)$. Statistical comparison of times: means with identical upper-case letters in the same column do not differ significantly $(P \leq 0.05)$. 


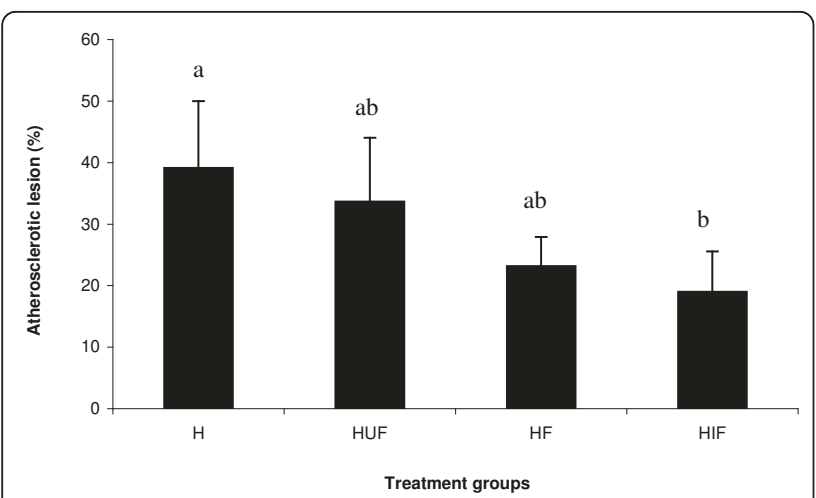

Figure 1 Percentage of aortic area of whole aorta (thoracic and arch) covered with lesion. The bar graphs represent the average $(n=6)$ for each group with standard errors. $\mathrm{C}=$ control; $\mathrm{H}=$ hypercholesterolemic; HUF = hypercholesterolemic plus unfermented soy product, $\mathrm{HF}=$ hypercholesterolemic plus fermented soy product, HIF = hypercholesterolemic plus isoflavonesuplemented soy fermented product.

on the other, and a positive correlation between HDL-C and these microorganisms genera (Table 4). The Enterobacteria population was negatively correlated only with the HDL-C. Finally the levels of autoantibody against oxidized LDL and the size of atherosclerotic lesion were negatively correlated with the Clostridium spp. count. For the most of analyzed parameters, the correlations

Table 3 Fecal bacterial counts (log cfu/g) in rabbits during the experimental period

\begin{tabular}{|c|c|c|c|c|}
\hline Groups & T0 & T60 & T0 & T60 \\
\hline & \multicolumn{2}{|c|}{ Enterococcus spp. } & \multicolumn{2}{|c|}{ Lactobacillus spp. } \\
\hline C & $5.87 \pm 0.08^{B}$ & $6.90 \pm 0.01^{\mathrm{A}}$ & $6.51 \pm 0.02^{\mathrm{B}}$ & $6.99 \pm 0.02^{\mathrm{A}}$ \\
\hline $\mathrm{H}$ & $7.26 \pm 0.01^{\mathrm{A}}$ & $6.85 \pm 0.01^{\mathrm{B}}$ & $8.07 \pm 0.11^{\mathrm{A}}$ & $7.17 \pm 0.01^{B}$ \\
\hline HUF & $7.23 \pm 0.04^{B}$ & $7.50 \pm 0.02^{\mathrm{A}}$ & $8.92 \pm 0.04^{\mathrm{A}}$ & $8.11 \pm 0.01^{B}$ \\
\hline HF & $6.60 \pm 0.01^{B}$ & $7.97 \pm 0.02^{\mathrm{A}}$ & $7.28 \pm 0.02^{\mathrm{B}}$ & $8.55 \pm 0.05^{\mathrm{A}}$ \\
\hline \multirow[t]{2}{*}{ HIF } & $5.27 \pm 0.01^{\mathrm{B}}$ & $7.68 \pm 0.03^{\mathrm{A}}$ & $7.50 \pm 0.03^{B}$ & $8.16 \pm 0.02^{A}$ \\
\hline & \multicolumn{2}{|c|}{ Bifidobacterium spp. } & \multicolumn{2}{|c|}{ Enterobacteria } \\
\hline C & $5.46 \pm 0.11^{B}$ & $6.56 \pm 0.01^{\mathrm{A}}$ & $8.81 \pm 0.06^{\mathrm{A}}$ & $7.86 \pm 0.04^{B}$ \\
\hline $\mathrm{H}$ & $8.54 \pm 0.01^{\mathrm{A}}$ & $6.91 \pm 0.03^{B}$ & $8.16 \pm 0.01^{\mathrm{A}}$ & $6.71 \pm 0.02^{B}$ \\
\hline HUF & $9.04 \pm 0.02^{\mathrm{A}}$ & $7.93 \pm 0.01^{B}$ & $8.32 \pm 0.03^{\mathrm{A}}$ & $6.96 \pm 0.02^{\mathrm{B}}$ \\
\hline HF & $7.61 \pm 0.01^{B}$ & $8.29 \pm 0.02^{A}$ & $7.00 \pm 0.05^{\mathrm{A}}$ & $3.47 \pm 0.05^{\mathrm{B}}$ \\
\hline HIF & $8.59 \pm 0.03^{A}$ & $8.07 \pm 0.12^{B}$ & $7.59 \pm 0.23^{\mathrm{A}}$ & $6.64 \pm 0.05^{\mathrm{B}}$ \\
\hline \multicolumn{5}{|c|}{ Clostridium spp. } \\
\hline$C$ & $8.77 \pm 0.05^{\mathrm{A}}$ & $7.85 \pm 0.07^{B}$ & & \\
\hline $\mathrm{H}$ & $8.69 \pm 0.01^{A}$ & $7.33 \pm 0.01^{B}$ & & \\
\hline HUF & $8.90 \pm 0.02^{\mathrm{A}}$ & $7.67 \pm 0.01^{\mathrm{B}}$ & & \\
\hline HF & $7.41 \pm 0.05^{\mathrm{A}}$ & $7.53 \pm 0.11^{\mathrm{A}}$ & & \\
\hline HIF & $8.69 \pm 0.05^{A}$ & $8.04 \pm 0.01^{B}$ & & \\
\hline
\end{tabular}

Groups: $\mathrm{C}=$ control, $\mathrm{H}=$ hypercholesterolemic, $\mathrm{HUF}=$ hypercholesterolemic plus unfermented soy product, $\mathrm{HF}=$ hypercholesterolemic plus fermented soy product, HIF = hypercholesterolemic plus isoflavone-supplemented soy fermented product. T0 = before the start of the study, T60 = end of the ingestion period. Statistical comparison of times: means with identical uppercase letters in the same row do not differ significantly ( $P \leq 0.05)$. were observed only when the values of control group (without induced hypercholesterolemia) were not considered.

\section{Discussion}

Daily ingestion of aqueous soy extract fermented with Enterococcus faecium CRL 183 and Lactobacillus helveticcus 416, supplemented or not with isoflavones, was found to reduce the risk of cardiovascular disease by improving the lipid profile and inhibiting oxLDL Ab formation. Earlier studies have shown the hypolipemiant and anti - atherogenic properties of this product in various animal models and clinical trials [8-11].

In the colon, the microbiota is comprised mainly of anaerobes such as Bacteroides spp., Porphyromonas spp., Bifidobacterium spp., Lactobacillus spp. and Clostridium spp. The composition of human microbiota remains relatively constant throughout the adult life, but it may be influenced by age, diet and socio-economic conditions and, mainly, by the use of antibiotics [24,25].

Some bacterial genera in the gut, such as Bifidobacterium spp. and Lactobacillus spp., are considered beneficial to the host, while others can be potentially pathogenic $[26,27]$. In this context, there is a consensus among researchers that several human disease states have benefited from the use of probiotics, most notably, diarrhea, some inflammatory bowel diseases, infectious disorders, irritable bowel syndrome and dyslipidemia [25].

After 60 days of the experiment, intake of probiotic soy product was related to significant increases $(\mathrm{P}<0.05)$ in Lactobacillus spp. and Bifidobacterium spp. counts indicating that the presence of the probiotic microorganisms (E. faecium CRL183 and L. helveticus 416) stimulated the growth of beneficial microorganisms (Lactobacillus spp. and Bifidobacterium spp.), since the unfermented product was not able to increase the populations of these fecal bacteria genera. Similar results were observed by other researchers, when rats on a beef-based diet were treated with the same fermented product, without isoflavone supplementation [26].

The increase in the population of intestinal bifidobacteria represents a beneficial effect for the host, since these microorganisms are involved in the production of short chain fatty acids (SCFA), reduction of intestinal $\mathrm{pH}$, reduction of putrefaction products, inhibition of the growth of pathogens and immunomodulation [28].

The population of Enterococcus spp. decreased only in the hypercholesterolemic group $(\mathrm{H})$. However, it is important to emphasize that the animals under treatment with the probiotic product (HF and HIF) exhibited the largest increases in number of microrganisms of this genus, demonstrating the probable persistence in the gut of the probiotic $E$. faecium strain during the feeding period. The health properties of E. faecium CRL 183, used as 
Table 4 Correlation ( $r$ value) between bacterial populations, lipid parameters and lesion size

\begin{tabular}{lccccc}
\hline Bacterial population & Total Cholesterol & non-HDL-C & HDL-C & ox-LDL Ab & Lesion size \\
\hline Enterococcus spp. & $-\mathbf{0 . 9 8}(0.19)$ & $-\mathbf{0 . 9 8}(0.18)$ & $\mathbf{0 . 9 7}(0.66)$ & $-\mathbf{0 . 9 0}(0.45)$ & $-\mathbf{0 . 8 4}(0.09)$ \\
Lactobacillus spp. & $-\mathbf{0 . 9 9}(0.37)$ & $-\mathbf{0 . 9 9}(0.32)$ & $\mathbf{0 . 9 5}(0.57)$ & $-\mathbf{0 . 9 6}(-0.33)$ & $-\mathbf{0 . 7 8}(0.26)$ \\
Bifidobacterium spp. & $-\mathbf{0 . 9 9}(0.27)$ & $-\mathbf{0 . 9 9}(0.27)$ & $\mathbf{0 . 9 0}(0.57)$ & $-\mathbf{0 . 9 9}(-0.40)$ & $-\mathbf{0 . 8 1}(0.19)$ \\
Enterobacteria & $0.60(0.27)$ & $0.6022(-0.27)$ & $-\mathbf{0 . 7 9}(-0.57)$ & $0.40(0.07)$ & $0.43(-0.24)$ \\
Clostridium spp. & $-0.49(-0.49)$ & $-0.49(-0.50)$ & $0.37(0.41)$ & $-\mathbf{0 . 7 6}(0.73)$ & $-\mathbf{0 . 7 6}(-0.66)$ \\
\hline
\end{tabular}

Correlation coefficients with an $r$ superior of 0.7 are shown in bold face type.

Values including control animals are presented in parentheses..

the starter culture in the fermented soy product, have been extensively studied and include: inhibition of breast and colon cancer $[29,30]$, prevention of osteoporosis, modulation of the immune system [31] and hypocholesterolemic effect [7-10].

The enterobacteria group is represented mainly by Escherichia coli, Salmonella spp., Shigella spp., Yersinia enterocolitica, Klebsiella spp., Proteus spp. and Citrobacter spp. and is related to intestinal and extra-intestinal infections. In this study, all the animals groups showed reduction in the enterobacteria population, with the most expressive results being obtained with probiotic fermented soy product (HF) ingestion. The inhibition of potentially pathogenic bacteria by a probiotic could be related to the production of various acids, hydrogen peroxide or bacteriocins, the competition for nutrients or adhesion receptors, anti-toxin action and stimulation of the immune system [32-34].

We also observed a reduction on Clostridium spp. after ingestion of unfermented soy product and isoflavonesupplemented soy product. However, the fermented soy product alone (HF) did not alter the Clostridium spp. population. In an earlier study, it was found that the same fermented soy product led to an increase in the number of viable cells of Clostridium spp. in the feces of rats fed on a beef-based diet [26]. The possible explanation for this observation was that the E. faecium CRL 183 or the metabolites generated during fermentation promote the increase in the Clostridium spp. population. Clostridium spp. is a major component of normal anaerobic microbiota and some species may cause infectious diseases in humans [35]. However, in this study the identification of bacteria to species level was not done and it is thus not possible to decide whether the rise in the Clostridium spp. population is prejudicial or not.

Cardiovascular diseases are related to dyslipidemia (high levels of total cholesterol and low-density lipoprotein and low levels of high-density lipopprotein). The present study showed a strong correlation between microbiota composition and lipid profile. Population of Enterococcus spp., Lactobacillus spp. and Bifidobacterium spp. were negatively associated with total cholesterol, non-HDL-cholesterol, autoantibodies against oxidized LDL (oxLDL Ab) and lesion size. Clostridium spp. viable cells in the feces were negatively associated with antibodies against oxidized LDL (oxLDL Ab) and lesion size. HDL-C levels were positively associated with Lactobacillus spp., Bifidobacterium spp. and Enterococcus spp. populations.

Several studies have reported the beneficial effects of bifidobacteria and lactobacilli on lipid metabolism, when they are administered as probiotics or when their growth is stimulated by prebiotics [4,36-38]. Martinez et al (2009) [4] showed that consumption of grain sorghum lipid extract (GSL) improved the high-density lipoprotein equilibrium (HDL/non-HDL cholesterol) and this effect was associated with alteration in gut microbiota. Bifidobacterium spp. population exhibited a strong positive correlation with plasma cholesterol levels $(r=0.75$; $\mathrm{P}=0.001$ ). Wang et al. (2009) [39] showed that ingestion of a diet supplemented with lyophilized L. plantarum MA2 ( $10^{11} \mathrm{CFU} /$ day) significantly lowered serum total cholesterol, low-density lipoprotein cholesterol, and triglycerides level in mice. The authors also observed an increase in the Lactobacillus spp. and Bifidobacterium spp. populations.

In vitro experiments, have demonstrated that $E$. faecium CRL183 reduces cholesterol by 53.85\% [40] and 51.20\% [41]. We have also reported that the soy product fermented with E. faecium CRL 183 and Lactobacillus helveticus 416 can improve the lipid parameters in animal and human tests [7-9].

The mechanism of hypolipemiant action, although not completely known, involves assimilation of cholesterol, deconjugation of bile salts and fermentation of nondigestible carbohydrates from the diet, producing shortchain fatty acids $[42,43]$.

The first hypothesis suggests that some microorganisms may assimilate cholesterol or incorporate this substance into the cell membrane, but this is not the consensus [44]. A second hypothesis considers that some bacterial species (such as bifidobacteria, lactobacilli, clostridia and streptococci) exhibit bile salt hydrolase activity being able to hydrolyze bile acids. Cholic and deoxycholic acids, bile acids produced from cholesterol by hepatocytes, are conjugated with glycine and 
taurine, respectively [45]. Desconjugated bile acids are not absorbed by the large intestine and are excreted through the feces and urine. In this situation, more cholesterol is used to synthesize bile acids, leading to a fall in blood cholesterol levels $[37,45,46]$. Finally, some bacterial species in the large intestine ferment unabsorbed carbohydrates to produce short-chain fatty acids (SCFA).

Acetate is the major SCFA produced, but the amount of propionate and butyrate varies. Several studies show that acetate increases total cholesterol while propionate reduces the hypercholesterolemic effect caused by acetate $[45,47]$. Butyrate is known to inhibit liver cholesterol synthesis and provide a source of energy for human colon epithelial cells, while propionate is involved in the inhibition of the synthesis of fatty acids in the liver, thereby lowering the rates of triacylglycerol secretion and the rate of cholesterol synthesis, which could lead to the improvement of plasma cholesterol levels [48]. The hypolipidemic effect of probiotic bacteria probably involves production of sufficient propionate and butyrate to offset the effects of acetate. An increase in the number of lactic acid bacteria, such as lactobacilli and bifidobacteria in the gut was correlated with a higher concentration of lactic acid, that may be converted in acetic and butyric acid [49]. In an in vitro experiment, Meimandipou et al, (2009) [50] found that L. agilis JCM 1048 and L. salivarius ssp. salicinius JCM 1230 increased the total anaerobes, lactobacilli and bifidobacteria population after $24 \mathrm{~h}$ incubation and enhanced the production of lactate, propionate and butyrate. In the present work, SCFA were not analyzed and further studies are necessary to investigate this point. However, we believe that a beneficial modification of the microbiota composition, observed on consumption of the fermented soy product, with or without isoflavones, could collaborate to increase of the propionate and butyrate production, so that cholesterol concentrations may be altered positively.

Oxidative modification of LDL induces the formation of immunogenic epitopes in the LDL, leading to the generation of antibodies against oxidized LDL (oxLDL Ab) [51]. We found that generation of autoantibodies against ox LDL was highest $(\mathrm{P}<0.05)$ in the hypercholesterolemic group $(\mathrm{H})$ and that the intake of soy fermented products (HF and HIF) prevented the rise in this parameter during the experiment. The reduction in non-HDL-C concentrations (LDL+VLDL+IDL), with a consequent reduction in LDL particles available for oxidation, observed in the HF and HIF groups could, partially, explain this effect. The importance of oxLDL Ab in atherogenesis remains unclear.

Infections have been thought to cause or promote atherosclerosis by increasing pro-atherosclerotic changes in vascular cells. These changes involve a rise in scavenger receptor expression, enhancement in uptake of cholesterol and modified low-density lipoprotein and an increase in the expression of adhesion molecules and inflammatory cytokines, leading to atherosclerotic plaque vulnerability [52]. Considering that atherosclerosis is a chronic immune inflammatory disease, it is possible that increased populations of Bifidobacterium spp., Lactobacillus spp. and Enterococcus spp., microorganisms that exhibit immunoregulatory properties, may be linked to the development of the atherosclerotic lesion $[29,53]$.

\section{Conclusions}

The results of this study suggest that daily ingestion of the probiotic soy product, supplemented or not with isoflavones, may contribute to a beneficial balance of the fecal microbiota. The findings also indicate that the modulation of microbiota is associated with an improved cholesterol profile and inhibition of atherosclerotic plaque formation.

\section{Abbreviations}

CVD: Cardiovascular Disease;CHD: Coronary Heart Disease; C: control, H: hypercholesterolemic, HUF: hypercholesterolemic plus unfermented soy product, HF: hypercholesterolemic plus fermented soy product; HIF: hypercholesterolemic plus isoflavone-supplemented fermented soy product (HIF);TC: Total Cholesterol; HDL-C: High Density Lipoprotein Cholesterol; LDLC: Low Density lipoprotein Cholesterol; VLDL: Very Low Density Lipoprotein Cholesterol; n-DHL-C: Non High Density Lipoprotein Cholesterol; oxLDL: oxidized Low Density Lipoprotein; oxLDL Ab: Autoantibodies against oxidized Low Density Lipoprotein, SCFA: short-chain fatty acids.

\section{Acknowledgements}

We would like to thank the Fundação de Amparo à Pesquisa do Estado de São Paulo (FAPESP) for financial support.

\section{Author details}

'Department of Food \& Nutrition, School of Pharmaceutical Sciences, Sao Paulo State University, Araraquara, SP, Brazil. ${ }^{2}$ Department of Clinical and Toxicological Analyses, School of Pharmaceutical Sciences, University of Sao Paulo, Sao Paulo, Brazil. ${ }^{3}$ Department of Clinical Analysis, School of Pharmaceutical Sciences, Sao Paulo State University, Araraquara, SP, Brazil.

\section{Authors' contributions}

DCUC: was involved in design, data collection, drafting the manuscript and revising it critically for important intellectual content.

JYS, DSPA, RCV, NDPS, MNR, RAP: participated in data collection, interpretation of results and drafting the manuscript.

EAR: was involved in design, drafting the manuscript and revising it critically for important intellectual content.

All authors read and approved the final manuscript.

\section{Competing interests}

The authors declare that they have no competing interests.

Received: 6 June 2011 Accepted: 29 July 2011 Published: 29 July 2011

\section{References}

1. Holmes E, Loo RL, Stamler J, Bictash M, Yap IK, Chan Q, Ebbels T, De lorio M, Brown IJ, Veselkov KA, Daviglus ML, Kesteloot H, Ueshima H, Zhao L, Nicholson JK, Elliott P: Human metabolic phenotype diversity and its association with diet and blood pressure. Nature 2008, 453:396-400

2. Kelly D, King T, Aminov R: Importance of microbial colonization of the gut in early life to the development of immunity. Mutat Res 2007, 622:58-69. 
3. Goff DA, Bertoni AG, Kramer H, Bonds D, Blumenthal RS, Tsai MY, Bruce M Psaty BM: Dyslipidemia Prevalence, Treatment, and Control in the MultiEthnic Study of Atherosclerosis (MESA). Circulation 2006, 113:647-656.

4. Martínez I, Wallace G, Zhang C, Legge R, Benson AK, Carr TP, Moriyama EN, Walter J: Diet-induced metabolic improvements in a hamster model of hypercholesterolemia are strongly linked to alterations of the gut microbiota. Appl Environm Microbiol 2009, 75:4175-4184.

5. Backhed F, Ding H, Wang T, Hooper LV, Koh GY, Nagy A, Semenkovich CF, Gordon JL: The gut microbiota as an environmental factor that regulates fat storage. Proc Natl Acad Sci 2004, 101:15718-15723.

6. Backhed F, Manchester JK, Semenkovich CF, Gordon JL: Mechanisms underlying the resistance to diet-induced obesity in germ-free mice. Proc Natl Acad Sci 2007, 104:979-984.

7. Rossi EA, Vendramini RC, Carlos IZ, Pei YC, Valdez GF: Development of a novel fermented soymilk product with potential probiotic properties. Eur Food Res Technol 1999, 209:305-307.

8. Rossi EA, Vendramini RC, Carlos IZ, Ueiji IS, Squinzari M, Silva SI, Valdez GF: Effects of a novel fermented soy product on the serum lipids of hypercholesterolemic rabbits. Ara Bras Cardiol 2000, 74:213-216.

9. Rossi EA, Vendramini CR, Carlos IZ, Oliveira MG, Valdez GF: Efeito de um novo produto fermentado de soja sobre lípides séricos de homens adultos normocolesterolêmicos. Arch Latinoam Nutr 2003, 53:47-51.

10. Rossi EA, Cavallini DCU, Carlos IZ, Vendramini RC, Damaso AR, Valdez GF: Intake of isoflavone-supplemented soy yogurt fermented with Enterococcus faecium lowers serum total cholesterol and non-HDL cholesterol of hypercholesterolemic rats. Eur Food Res Technol 2008, 228:275-282.

11. Cavallini DCU, Abdalla DSP, Vendramini RC, Bedani R, Bomdespacho LQ, Pauly-Silveira ND, Valdez GF, Rossi EA: Effects of isoflavone-supplemented soy yogurt on lipid parameters and atherosclerosis development in hypercholesterolemic rabbits: a randomized double-blind study. Lipids Health Dis 2009, 8:40

12. Allain CA, Poon LS, Chan CSG, Richmond W, Fu PC: Enzymatic determination of total serum cholesterol. Clin Chem 1974, 20:470-475.

13. Bergmeyer HW: Methods of enzymatic analysis. London: Academic Press; 1974, 1890-1893.

14. Song T, Lee S-O, Murphy PA, Hendrich S: Soy protein with or without isoflavones, soy germ and soy germ extract, and daidzein lessen plasma cholesterol levels in golden syrian hamsters. Exp Biol Med 2006, 228:1063-1068.

15. Liu J, Sempos C, Donahue RP, Dorn J, Trevisan M, Grundy SM: Joint Distribution of Non-HDL and LDL Cholesterol and Coronary Heart Disease Risk Prediction Among Individuals With and Without Diabetes. Diabetes Care 2005, 28:1916-1921

16. Damasceno NRT, Hiro G, Rodrigues FMD, Dias CTS, Okawabata FS, Abdalla DSP, Gidlund M: Soy protein isolate reduces the oxidizability of LDL and the generation of oxidized LDL autoantibodies in rabbits with diet-induced atherosclerosis. J Nutr 2000, 130:2641-2647.

17. Cavallini DCU, Pauly-Silveira ND, Abdalla DSP, Rossi EA: Effect of simvastatin on the generation of autoantibodies against oxidized LDL and progression of atherosclerosis in rabbits. Latin Am J Pharm 2010, 29:1419-1424.

18. Llera-Moya M, Rothblat GH, Glick JM, England JM: Etoposide treatment suppresses atherosclerotic plaque development in cholesterol-fed rabbits. Arterioscler Thromb Vasc Biol 1992, 12:1363-1370.

19. Edlund C, Beyer G, Hiemer-Bau M, Ziege S, Lode H, Nord CE: Comparative effects of moxifloxacin and clarithromycin on normal intestinal microflora. Scand J Infect Dis 2000, 32:81-85.

20. Yoshioka H, Iseki K, Fujita K: Development and difference of intestinal flora in the neonatal period in breast-fed and bottle-fed infants. Pediatrics 1993, 72:317-321.

21. Munoa FJ, Pares R: Selective medium for isolation and enumeration of Bifidobacterium spp. Appl Environ Microbiol 1988, 54:1715-1718.

22. Brigidi P, Vitali B, Swennen E, Bazzocchi G, Matteuzzi D: Effects of probiotic administration upon the composition and enzymatic activity of human fecal microbiota in patients with irritable bowel syndrome or functional diarrhea. Res Microbiol 2001, 152:735-741.

23. Marzotto M, Maffeis C, Paternoster T, Ferrario R, Rizzotti L, Pellegrino M, Dellaglio F, Torriani S: Lactobacillus paracasei A survives gastrointestinal passage and affects the fecal microbiota of healthy infants. Res Microbiol 2006, 157:857-866
24. Neish AS: Microbes in gastrointestinal health and disease. Gastroenterology 2009, 136:65-80.

25. Quigley EMM: Prebiotics and probiotics, modifying and mining the microbiota. Pharmacol Res 2010, 61:213-218.

26. Bedani R, Pauly-Silveira ND, Roselino MN, Valdez GF, Rossi EA: Effect of fermented soy product on the fecal microbiota of rats fed on a beefbased animal diet. J Sci Food Agric 2010, 90:233-238.

27. Bourlioux P, Koletzko B, Guarne F, Braesco V: The intestine and its microflora are partners for the protection of the host: report on the Danone Symposium "The Intelligent Intestine", held in Paris, 14 June 2002. Am J Clin Nutr 2003, 78:675-678

28. Mitsuoka T: Bifidobacteria and their role in human health. $J$ Ind Microbio 1990, 6:263-268.

29. Kinouchi FL: "logurte" de soja como coadjuvante no cancer de mama. PhD thesis São Paulo State University, Clinical Analysis Department; 2006.

30. Sivieri K, Spinardi-Barbisan ALT, Barbisan LF, Bedani R, Pauly ND, Carlos IZ Rossi EA: Probiotic Enterococcus faecium CRL 183 inhibit chemically induced colon cancer in male Wistar rats. Eur Food Res Technol 2008, 228:231-237

31. Vendramini AP: Efeito da ingestão de um produto de soja fermentado com Enterococcus faecium e Lactobacillus helveticus na produção de citocinas, óxido nítrico e peróxido de nitrogênio. Master degree dissertation São Paulo State University, Clinical Analysis Department; 2002.

32. Steer T, Carpenter H, Tuohy K, Gibson GR: Perspectives on the role of the human gut microbiota and its modulation by pro- and prebiotics. Nutr Res Rev 2000, 13:229-254

33. Fooks $L$, Gibson GR: Probiotics as modulators of the gut flora. Br J Nutr 2002, 88(S1):39-49.

34. Rakoff-Nahoum S, Paglino J, Eslami-Varzaneh F, Edberg S, Medzhitov R: Recognition of commensal microflora by toll-like receptors is required for intestinal homeostasis. Cell 2004, 118:229-241.

35. Bouhnik $Y$, Achour $L$, Paineau D, Riottot AA, Bournet F: Four-week short chain fructooligosaccharides ingestion leads to increasing fecal bifidobacteria and cholesterol excretion in healthy elderly volunteers. Nutr J 2007

36. Nauruszewicz M, Johansson M-L, Zapolska-Downar D, Bukowska H: Effect of Lactobacillus plantarum $299 \mathrm{v}$ on cardiovascular disease risk factor in smokers. Am J Clin Nutr 2002, 76:1249-1255.

37. Park YH, Kim JG, Shin YW, Kim HS, Kim YJ, Chun T, Kim SH, Whang KY: Effects of Lactobacillus acidophilus 43121 and a mixture of Lactobacillus casei and bifidobacterium longum on the serum cholesterol level and fecal sterol excretion hypercholesterolemia induced pigs. BiosCi Biotechnol Biochem 2008, 72:595-600.

38. Xiao JZ, Kondo S, Takahashi N, Miyaji K, Oshida K, Hiramatsu A, Iwatsuki K, Kokubo S, Hosono A: Effects of milk products fermented by bifidobacterium longum on blood lipids in rats and healthy adult male volunteers. J Dairy Sci 2003, 86:2452-2461.

39. Wang $Y, X u N, X i$ A, Ahmed Z, Zhang B, Bai X: Effects of Lactobacillus plantarum MA2 isolated from Tibet kefir on lipid metabolism and intestinal microflora of rats fed on high-cholesterol diet. Appl Microbiol Biotechnol 2009, 84:341-347.

40. Rossi EA, Giori GS, Holgado APR, Valdez GF: In vitro effect of Enterococcus faecium and Lactobacillus acidophilus on cholesterol. Microbiologiealiments-nutrition 1994, 12:267-270.

41. Saavedra L, Taranto MP, Sesma F, Valdez GF: Homemade traditional cheeses for the isolation of probiotic Enterococcus faecium strains. Int J Food Microbiol 2003, 88:241-245.

42. Pereira DIA, Gibson GR: Cholesterol assimilation by lactic acid bacteria and bifidobacteria isolated from the human gut. Appl Environ Microbiol 2002, 68:4689-4693.

43. Zhao JR, Yang $\mathrm{H}$ : Progress in the effect of probiotics on cholesterol and its mechanism. Wei Sheng Wu Xue Bao 2005, 45:315-319.

44. Kimoto $\mathrm{H}$, Ohmomo S, Okamoto T: Cholesterol removal from media by lactococci. J Dairy Sci 2002, 85:3182-3188.

45. St-Onge M-P, Farnworth ER, Jones PJH: Consumption of fermented and nonfermented dairy products: effects on cholesterol concentrations and metabolism. Am J Clin Nutr 2000, 71:674-681.

46. Begley M, Hill C, Gahan CGM: Bile salt hydrolase activity in probiotics. Appl Environ Microbiol 2006, 72:1729-1738.

47. Wolever TMS, Spadafora PI, Eshuis H: Interation between colonic acetate and propionate in humans. Am J Clin Nutr 1991, 53:681-687. 
48. Trautwein EA, Rieckhoff $D$, Erbersdobler HF: Dietary Inulin Lowers Plasma Cholesterol and Triacylglycerol and Alters Biliary Bile Acid Profile in Hamsters. J Nutr 1998, 128:1937-1943.

49. Duncan $\mathrm{SH}$, Louis P, Flint HJ: Lactate-utilizing bacteria, isolated from human feces, that produce butyrate as a major fermentation product. Appl Environm Microbiol 2004, 70:5810-5817.

50. Meimandipou A, Shuhaimi M, Hair-Bejo M, Azhar K, Kabeir BM, Rasti B, Yazid AM: In vitro fermentation of broiler cecal content: the role of lactobacilli and $\mathrm{pH}$ value on the composition of microbiota and end products fermentation. Lett Appl Microbiol 2009, 49:415-420.

51. Craig W: Autoantibodies against oxidized low density lipoprotein: a review of clinical findings and assay methodology. J Clin Lab Anal 1995, 9:70-74.

52. Epstein SE, Zhu J, Burnett MS, Zhou YF, Vercellotti G, Hajjar D: Infection and atherosclerosis: potential roles of pathogen burden and molecular mimicry. Arterioscler Thromb Vasc Biol 2000, 20:1417-20.

53. Leahy SC, Higgins DG, Fitzgerald GF, Van Sinderen D: Getting better with bifidobacteria. J Appl Microbiol 2005, 98:1303-1315.

doi:10.1186/1476-511X-10-126

Cite this article as: Cavallini et al:: Influence of a probiotic soy product on fecal microbiota and its association with cardiovascular risk factors in an animal model. Lipids in Health and Disease 2011 10:126.

\section{Submit your next manuscript to BioMed Central and take full advantage of:}

- Convenient online submission

- Thorough peer review

- No space constraints or color figure charges

- Immediate publication on acceptance

- Inclusion in PubMed, CAS, Scopus and Google Scholar

- Research which is freely available for redistribution

Submit your manuscript at www.biomedcentral.com/submit 